\title{
PUNIR OS POBRES EM TEMPOS DE PANDEMIA
}

\author{
Elinton Fabio Romão ${ }^{1}$ \\ Universidade Federal Fluminense \\ elintonfabio@id.uff.br
}

\section{RESUMO:}

O presente artigo busca trazer elementos das discussões acerca do fim do Estado-providência com base nos livros Punir os Pobres (2007), do sociólogo Loïc Wacquant (2007), e A Crise do Estado Providência (1997), do historiador Pierre Rosanvallon, que tratam como políticas neoliberais de desregulação da economia produziram uma nova espacialização da sociedade, impactando em suas sociabilidades evidenciadas hoje pela pandemia da COVID-19.

Palavras-chave: Racismo; Subemprego; Punição.

\section{INTRODUÇÃO}

A continuidade da punição aos pobres evidenciada pela atual pandemia da COVID19, não apenas aos pobres, ela é punição a outras corporeidades e sociabilidades que tem no sistema colonial moderno, onde foi fundada a relação raça/trabalho, e a manutenção deste sistema que foi e é um mecanismo de controle social (QUIJANO, 2005), mais do que as questões de mão de obra foi à criação de sub cidadanias (SCHWARCZ, 2007) que gerou sociedades estruturadas no racismo (ALMEIDA, 2018). Os corpos negros renegados a escravidão, e, posteriormente, ao subemprego; das senzalas aos cortiços, dos cortiços às favelas; escravos de ganho, do eito, das minas, mucamas gradativamente, em sucessivas gerações, migraram para boias-frias; camelôs, flanelinhas, porteiros, empregadas domésticas etc. em moradias precárias; a reprodução mais barata possível da classe trabalhadora superexplorada. Aqui identificamos os cortes de políticas sociais pós-1970, apontados por Wacquant (2007) e Rosanvallon (2007), que percebem a sociedade da diferença com a punição aos pobres adotadas nos Estados Unidos ainda na década de 80 e se aprofundam nos países de terceiro mundo pós 1990 e no Brasil em especial pós 2016, com a desregulação das leis trabalhistas.

\footnotetext{
${ }^{1}$ Aluno de Graduação da Universidade Federal Fluminense. Membro do Laboratório de Estudos dos Movimentos Sociais e Territorialidades.

AO CITAR ESTE TRABALHO, UTILIZE A SEGUINTE REFERÊNCIA:

ROMÃO, Elinton Fabio. Punir os pobres em tempos. Revista Ensaios de Geografia, Niterói, vol. 5, nº 10, p. 33-38, julho de 2020.

Submissão em: 05/05/2020. Aceite em: 09/06/2020.

Universidade Federal Fluminense, Niterói, RJ - Brasil.
} 


\section{SOCIEDADE DA DIFERENÇA E PANDEMIA}

Os estados neoliberais fundados na fragmentação do estado de bem estar social, que aqui concordamos com Rosavallon, no entendimento que mais do que limitações econômicas, crise fiscal, o que ocorreu foi rompimento do pacto da sociedade de igualdade onde os trabalhadores europeus foram desde o fim do século XIX, ainda no liberalismo, ganhando direitos trabalhistas e sociais e o entendimento que caberia ao estado amenizar os efeitos da pobreza e realizar o ordenamento urbano (DARDOT; CLAVAL, 2016).

Essa sociedade da igualdade ganhou mais força nos Estados Unidos pós-crise de 1929, no pós-fim da segunda Guerra Mundial e nas lutas pelos direitos civis dos anos 60 e 70 . Esse estado de igualdade para Rosavallon será confrontado por questões internas ao capitalismo, um sistema que valoriza a individualidade, o discurso da meritocracia e a individualidade atrelado a todo avanço tecnológico do novo meio técnico-informacional (SANTOS, 1996) que se apresentam pós-1970, onde solicitava a desregulação dos sistemas financeiros, fiscais e trabalhista. Esse novo sistema (neoliberalismo) se espalhou pelo mundo via ação propagandista dos meios de comunicação e do Banco Mundial, OMC e FMI fortalecendo $a$ sociedade da diferença, de um novo darwinismo social (DARDOT; LAVAL, 2016).

Com o corte sistemático de políticas públicas, executados principalmente em momentos de crescimento econômico, como mostrado por Wacquant, em "Punir os Pobres" (2007) ao tratar os cortes em programas sociais e o endurecimento das leis com penas de prisão, e com penas cada vez mais longas, durante o Governo de Bill Clinton (1993-2001), enterrando de vez os argumentos economicistas para os cortes.

Quando olhamos os dados da pandemia da COVID-19 nos Estados Unidos, fica claro que toda essa desregulação, que levou a concentração de riqueza a renda do $1 \%$ mais ricos triplicou e dos $10 \%$ mais ricos dobrou enquanto ocorreu o encolhimento da classe média de $60 \%$ para 50\%, aumento dos mais pobres com diminuição pela metade da participação desse segmento no total da economia chegando em 2018 a apenas $12,5 \%{ }^{2}$. A economia americana conseguiu vencer a "crise do emprego" encadeada pós-crise de 2008 (crise de endividamento provocada justamente pela desregulamentação do sistema financeiro) descendo de $12 \%$ em

\footnotetext{
${ }^{2}$ Em 40 anos, metade dos EUA ganhou U\$200 a mais. Disponível em:

$<$ https://temas.folha.uol.com.br/desigualdade-global/estados-unidos/em-40-anos-metade-dos-eua-ganhou-so-us200-a-mais.shtml>. Acessado em: 05 de maio de 2020.
} 
2008 para 3,5\% em fevereiro de 2020, mas o mesmo não foi acompanhado pela diminuição da pobreza, devidos aos baixos salários e poucos direitos. O desemprego deve alcançar 12\%, chegando até a $20 \%$ nos bairros negros e latinos devido à pandemia ${ }^{3}$.

Em um país em que o acesso a saúde é privado, geralmente obtido no acesso ao emprego como um direito trabalhista, a disseminação do subemprego como norma, e a livre negociação entre patrões e empregados, coloca 30 milhões de americanos, em sua maioria negros, sem nenhum tipo de cobertura e 40 milhões com planos de saúde básicos ${ }^{4}$.

Após quase dois meses minimizando o potencial destrutivo da COVID-19, insistindo em manter a economia aberta, o governo norte americano realizou uma ampla testagem no fim de março, onde foram detectados mais de 100.000 casos e já se registrava mais de 1550 mortes. No início de março chega a mais de 73.000 mortes e um universo de 1.250 .000 pessoas contaminadas e o governo americano vêm tomando medidas de reabertura da economia, enquanto Nova York que foi o epicentro da pandemia diminui os casos de contaminação, mas em contrapartida surgem cada vez mais casos em outras cidades do país. No estado norte americano de Illinois apenas $15 \%$ da população é negra, no entanto, essa parcela da população representa $40 \%$ dos casos de contaminação e $35 \%$ dos óbitos por COVID-19; Quando observado apenas a capital do estado de Illinois, a cidade de Chicago, onde $30 \%$ dos moradores são negros, eles representam mais da metade dos contaminados e $70 \%$ dos óbitos 5 .

O subemprego coloca os corpos negros na linha de frente da contaminação, trabalhadores mal remunerados, que não possuem reserva financeira para poderem se manter em isolamento social, e não tem poder de negociação junto aos seus patrões, já que os sindicatos são praticamente inexistentes. Situação que se agrava quando olhamos para a propagação da doença nos países de terceiro mundo, seguidores das políticas neoliberais norte-americanas, onde além de imperar o subemprego e pouco acesso ao sistema de saúde,

\footnotetext{
${ }^{3}$ COVID-19 afeta duramente bairro de Nova York. R7. Disponível em:

$<$ https://noticias.r7.com/internacional/covid-19-afeta-duramente-bairro-de-nova-york-de-maioria-latina16042020>. Acessado em: 05 de maio de 2020.

${ }^{4}$ A ameaça do coronavírus nos EUA, onde milhões não tem licença médica e saúde pública. BBC. Disponível em: 〈https://www.bbc.com/portuguese/internacional-51746841>. Acessado em: 05 de maio de 2020.

${ }^{5}$ Negros americanos registram números alarmantes de corona vírus. O GLOBO. Disponível em: $<$ https://oglobo.globo.com/mundo/negros-americanos-registram-numeros-alarmantes-de-infeccoes-porcoronavirus-1-24357187>. Acessado em: 05 de maio de 2020.
} 
existem problemas de moradias precárias, acentuado, principalmente, pelos baixos níveis de saneamento básico, que já provoca surto de doenças nesses países.

É só lembrarmos dos altos índices de tuberculose na cidade do Rio de Janeiro, como mostrado pelo historiador Sidney Chalhou na obra "Cidade Febril" (2017), é um problema desde fim do Império e início da República onde apesar da tuberculose matar muito mais pessoas, o governo concentrou-se no combate à febre amarela que vitimava muito menos pessoas. Porém essas eram brancas, o que nos remete a análise de Silvia Aguião ao analisar durante o governo Lula a implementação de políticas voltadas para a população LGBT onde ela nos traz a indagação "Quais Políticas? Para Quais Sujeitos?” (2013), seguindo a fala de uma enfermeira americana, em entrevista à BBC, quando perguntada sobre os impactos diferenciados da COVID-19, ao responder: que aqui não tem raça, aqui tem racismo ${ }^{6}$.

Para nossa análise a atual pandemia da COVID-19 é o reflexo do rompimento do Estado-providenciadas, da sociedade da igualdade, do estado produtor e provedor de bens e serviços; substituída pelas políticas da sociedade da individualidade, superexploração e punição dos mais pobres. As redes sociais de apoio mútuo entre as pessoas foram quebradas pelo neoliberalismo; Biopolítica e governamentalidade neoliberal para uns (brancos pertencentes à classe média), para a maioria necropoder e Estado de Exceção.

As imagens das covas coletivas ligam os pobres de Nova York aos pobres de Manaus, as imagens dos corpos largados pelas ruas de Guayaquil ou em caminhões no Brooklyn que a qualquer hora podem se reproduzir em qualquer outro lugar do mundo, cidades em que as pessoas não têm dinheiro para enterrar seus familiares, a financeirização da vida, agora, mas do que nunca é financeirização da morte. Ninguém fala na responsabilidade dos políticos que minimizam os efeitos da COVID-19 em detrimento de vidas em prol da economia, é isso, afinal a função da democracia, um cheque em branco para a irresponsabilidade do mercado, assim como um rei Sol dispondo da vida de seus súditos.

Precisamos pensar qual o papel dos Estados, os governantes podem realmente dispor da vida de seus cidadãos pelo bem da economia? Economia de quem? Economizar para quem? A junção de "eco" e "nomia" virou o mundo de ponta cabeça. Seja o eco grego de

\footnotetext{
${ }^{6}$ Coronavírus: porque a população negra é desproporcionalmente afetada. BBC. Disponível em: $<$ https://www.bbc.com/portuguese/internacional-52267566>. Acessado em: 05 de maio de 2020.

AO CITAR ESTE TRABALHO, UTILIZE A SEGUINTE REFERÊNCIA:

ROMÃO, Elinton Fabio. Punir os pobres em tempos. Revista Ensaios de Geografia, Niterói, vol. 5, n 10, p. 33-38, julho de 2020.

Submissão em: 05/05/2020. Aceite em: 09/06/2020.

Universidade Federal Fluminense, Niterói, RJ - Brasil.
} 
casa, ou o eco efeito físico de reverberação do som, só tem efeito se a nomia, lei, for de todos para todos.

A importância de um sistema de saúde público e universal, demonstrada na atual pandemia, nos convoca a buscarmos a sociedade de igualdade partindo do reconhecimento de outras corporeidades (ELIAS, 2015), no entendimento que o espaço é reconhecido a partir do corpo e do local que esse corpo ocupa no espaço, que conforma toda outra relação de pertencimento, propriedade e uso, gerando outras sociabilidades (MOREIRA, 2005). Para descolonizar o pensamento e pensarmos em outras propostas de meio técnico-científicoinformacional, que aqui pensamos nas contra geografias. Uma Antigeopolítica que seja um tensionamento fundamental trazido pelos movimentos sociais dissidentes em "circuitos alternativos" de representações e práticas das geopolíticas hegemônicas: “A antigeopolítica trabalha com a equação propositiva de que um outro mundo é possível somente quando o mundo do outro é possível” (LIMA, 2013, p.156).

\section{REFERÊNCIAS BIBLIOGRÁFICAS}

AGUIÃO, S. Quais políticas, quais sujeitos? Sentidos da promoção da igualdade de gênero e raça no Brasil (2003 - 2015). Caderno Pagu [on-line], n. 51, 2017.

ALMEIDA, S. L. de. O que é racismo estrutural? Belo Horizonte: Letramento, 2018.

CHALHOUB, S. Cidade febril. $2^{\circ}$ edição. São Paulo: Companhia das Letras, 2017.

DARDOT, P.; LAVAL, C. A nova razão do mundo. São Paulo: Ed. Boitempo, 2016.

LIMA, E. L. de. A Corporeidade como um Recurso Metodológico da Geograficidade. Periódicos UFJF, vol.5, 2016.

LIMA, I. A geografia e o resgate da geopolítica. Revista Espaço Aberto, PPGG - UFRJ, vol. $3, n^{\circ} .2$, p. 149-168, 2013.

MOREIRA, R. Sociabilidade e espaço: as formas de organização geográfica das sociedades na era da terceira revolução industrial - um estudo de tendências. Agrária [on-line], São Paulo, vol. 2, p.93-108, 2005.

QUIJANO, A. A colonialidade: eurocentrismo e ciências sociais do saber. Perspectivas Latino Americanas. Buenos Aires: Clacso, 2005.

ROSANVALON, P. A crise do Estado providência. Brasília: Ed. UnB, 1997.

AO CITAR ESTE TRABALHO, UTILIZE A SEGUINTE REFERÊNCIA:

ROMÃO, Elinton Fabio. Punir os pobres em tempos. Revista Ensaios de Geografia, Niterói, vol. 5, nº 10, p. 33-38, julho de 2020.

Submissão em: 05/05/2020. Aceite em: 09/06/2020.

Universidade Federal Fluminense, Niterói, RJ - Brasil. 
SANTOS, M. A Natureza do Espaço. São Paulo: Editora Universidade de São Paulo, 2006.

SCHWARCZ, L. M. O espetáculo das raças. São Paulo: Companhia das Letras, 1993.

WACQUANT, L. Punir os pobres. Rio de Janeiro: Ed. Revan, 2007. 